\title{
AUTONOMIA PRIVADA E EDUCAÇÃO DOS FILHOS: LACUNAS E DÚVIDAS SOBRE A EDUCAÇÃO DOMICILIAR NO BRASIL
}

\author{
PRIVATE AUTONOMY AND CHILDREN'S EDUCATION: GAPS AND DOUBTS ABOUT HOME \\ EDUCATION IN BRAZIL
}

Alexandre Antonio Bruno da Silva ${ }^{1}$ André Studart Leitão ${ }^{2}$ Marcella Mourão de Brito ${ }^{3}$

\begin{abstract}
Resumo: Este ensaio se propõe a investigar a possibilidade de reconhecimento do direito à opção pela educação domiciliar no Brasil. Não obstante a educação familiar seja uma metodologia pedagógica praticada por diversas famílias no Brasil e no mundo, ela carece de previsão no ordenamento jurídico pátrio. À anomia contrapõem-se a dinâmica do mundo pós-moderno e a necessidade de revisão ou abertura semântica dos arquétipos legais para adequá-los às novas possibilidades de educação e formação. Em termos teóricos, a pesquisa gravita em torno da ponderação entre a autonomia privada, o paternalismo e a medida ideal de interferência do Estado nas relações sociais. Conclui-se pela garantia do direito de os pais escolherem o modelo de ensino que considerarem mais adequado para os filhos, desde que cumpridas determinadas diretrizes obrigatórias que assegurem a liberdade, sem descuidar da proteção máxima da criança e do adolescente. Para a pesquisa, utilizou-se basicamente o recurso bibliográfico, por meio da análise de livros, artigos publicados em coletâneas e periódicos, normas nacionais e internacionais, páginas oficiais e notícias que ilustram a importância da temática no contexto brasileiro, sobretudo em razão do julgamento iminente da questão pelo Supremo Tribunal Federal.
\end{abstract}

Palavras-chave: Educação domiciliar. Modernidade líquida. Direito à educação. Autonomia privada. Paternalismo.
Abstract: This essay proposes to investigate the possibility of recognizing the right to opt for home education in Brazil. Although family education is a pedagogical methodology practiced by several families in Brazil and in the world, it lacks foresight in the legal order of the country. Anomie contrasts the dynamics of the postmodern world and the need for revision or semantic opening of legal archetypes to adapt them to the new possibilities of education and training. In theoretical terms, the research gravitates around the balance between private autonomy, paternalism, and the ideal measure of state interference in social relations. It concludes by guaranteeing the right of parents to choose the model of education they consider most appropriate for their children, provided that certain mandatory guidelines that ensure freedom are respected, without neglecting the maximum protection of the child and the adolescent. For the research, the bibliographic resource was basically used, through the analysis of books, articles published in collections and journals, national and international norms, official pages and news that illustrate the importance of the theme in the Brazilian context, mainly due to the imminent judgment of the matter by the Federal Supreme Court. Keywords: Home education. Liquid modernity. Right to education. Private autonomy. Paternalism.

\footnotetext{
1 Doutor em Direito pela Pontifícia Universidade Católica de São Paulo; doutorando em Políticas Públicas pela Universidade Estadual do Ceará; Professor no Programa de Pós-Graduação stricto sensu do Centro Universitário Christus; alexandre.bruno@terra.com.br; https://orcid.org/0000-0003-2799-4036

2 Doutor e Mestre em Direito das Relações Sociais pela Pontifícia Universidade Católica de São Paulo; Procurador Federal. Professor do Programa de Pós-graduação stricto sensu do Centro Universitário Christus; andrestudart@hotmail.com; https://orcid.org/0000-0001-9681-943X

3 Especialista em Direito Processual Civil pela Universidade Anhanguera; mestranda em Processo e Direito ao Desenvolvimento pelo Centro Universitário Christus; Avenida Dom Luís, 911, Meireles, 60160-230, Fortaleza, Ceará, Brasil; marcellamouraob@gmail.com; https://orcid.org/0000-0003-2465-9136
} 


\section{Introdução}

A educação domiciliar (homeschooling) é um movimento social que preconiza o direito de pais ou responsáveis de conduzirem, por conta própria, o processo de formação educacional de seus filhos ou pupilos.

De acordo com o ordenamento jurídico pátrio, a criança e o adolescente devem ser protegidos, em primeiro plano, pela família. Nesse sentido, o art. 22 do Estatuto da Criança e do Adolescente (BRASIL, 1990b) prescreve que os pais são responsáveis pela condução e orientação do desenvolvimento de seus filhos.

No Brasil, diante da ausência de disposição legal expressa, a possibilidade de educação domiciliar exclusiva, longe da escola e do modelo tradicional, foi levada à seara jurídica. Inclusive, o Supremo Tribunal Federal admitiu a repercussão geral da temática nos autos do Recurso Extraordinário n. 888.815 (RIO GRANDE DO SUL, 2018).

Por força do art. 5, IV, da Constituição Federal (BRASIL, 1988) e do art. $6^{\circ}$ da Lei de Diretrizes e Bases da Educação (BRASIL, 1996), impõe-se aos pais e responsáveis o dever de matricular e manter os filhos, a partir de quatro anos de idade, em escola pública ou particular. Contudo, importante ponderar que o poder familiar garante aos pais o direito de fazer escolhas, observadas eventuais limitações de segunda ordem. Além disso, conforme a realidade socioeconômica do grupo familiar e da comunidade onde habita, a priori, não parece razoável impor aos responsáveis legais a obrigação de lançar mão dos deficientes serviços públicos de educação.

A problemática reside no fato de que, não obstante a educação familiar seja uma metodologia pedagógica praticada por diversas famílias brasileiras, ela carece de previsão normativa. À anomia contrapõem-se a dinâmica do mundo pós-moderno e a necessidade de revisão ou de abertura semântica dos arquétipos legais para adequá-los às novas possibilidades de educação e formação. Deve-se ponderar que a reflexividade promove inputs relevantes que levam à reestruturação dos padrões sociais (GIDDENS, 1991, p. 47). Com isso quer-se dizer que a efetividade do direito reclama sucessivas alterações, até porque não existe regra absoluta dentro de uma sociedade metamórfica. Portanto, reformas e ajustes normativos são indispensáveis para a garantia do equilíbrio das relações jurídicas. Questiona-se, pois, se o modelo brasileiro, que impõe a matrícula escolar, possui capacidade para acompanhar as descontinuidades e os mais variados pontos de inflexão. Um dos desdobramentos naturais da discussão consiste em analisar a postura paternalista do Estado e o seu grau de interferência nas relações sociais com base em métricas alinhadas a princípios centrais do direito pátrio.

Destarte, claramente se contrapõe à concepção paternalista do Estado da ideia de autonomia privada. Afinal, a quem compete o direito de decidir a trajetória educacional de crianças e adolescentes? A discussão, evidentemente, pressupõe a análise da regulação normativa da educação 
básica no Brasil e de sua respectiva judicialização, bem como de modelos alternativos de educação, extraídos do direito comparado.

\section{A modernidade líquida e as escolhas pessoais}

O conceito de modernidade líquida, de Bauman (2001), é de suma importância para a compreensão do movediço tecido social, principalmente no que diz respeito à dinâmica das relações familiares.

Para Bauman (2001), a história da modernidade e da nova ordem encontrada nos dias de hoje é considerada fluida, pois, diferente dos sólidos, não mantém sua forma com facilidade. Ao contrário, move-se facilmente, escorre, não fixa espaço nem prende o tempo. Diferentemente do sólido, o líquido não é facilmente contido. Os sólidos são estáticos, imóveis e ocupam espaço.

Sob esse viés, a sociedade contemporânea constitui-se um ambiente fluido, extremamente suscetível às mudanças decorrentes de fatores exógenos, a exemplo da tecnologia e de sua reflexividade. As práticas sociais são constantemente examinadas e reformadas à luz de informação renovada sobre essas próprias práticas, alterando, assim, constitutivamente, seu caráter (GIDDENS, 1991, p. 47). Altera-se a percepção social de momento e de valores com extrema tranquilidade.

À luz da doutrina de Bauman (2001, p. 14), indaga-se: pode-se atribuir ao ensino escolar obrigatório a ideia de "sólido", o que demandaria a revisão de paradigmas estáticos e a redistribuição e realocação dos poderes de derretimento da modernidade?

A escola da modernidade sólida foi construída para proporcionar uma educação de longa duração, concreta e para toda a vida, baseada em uma estrutura imutável de aprendizagem. Portanto, solidificada em um modelo predeterminado, em que as pessoas eram educadas a se ajustar ao formato do mundo estático, que negava a possibilidade de pensamento crítico e de escolha pelo ser humano.

A mudança de paradigma contribui para a desconstrução do dogma da educação escolarizada. O processo de formação, moldado à maneira da modernidade sólida, que visava a uma educação estática e adequada à condição social da época, parece não se adequar ao novo modelo de sociedade, sagaz e aberta às interferências constantes de consumismo, individualização e dos meios cibernéticos. É uma sociedade em constante e rápida evolução (ALMEIDA; GOMES; BRACTH, 2008).

Portanto, a sociedade atual demanda novas escolhas, valores e liberdades. No mundo líquido, os padrões e configurações não são mais impostos, muito menos autoevidentes (BAUMAN, 2001). Ao contrário, são inúmeros, diversos e conflitantes, pois o indivíduo, ao mesmo tempo em que possui valores singulares, é bombardeado por informações, comandos e cargas em sua vida prática. Isso está em permanente mutação e não se estabelece de maneira inflexível no espaço.

Destarte, partindo do pressuposto de que o ser humano moderno protesta por liberdade, mobilidade e fluidez, deve-se questionar se os padrões sólidos impostos pelo Estado realmente dispõem de autoridade para tolher a autonomia privada. 


\section{0 contexto da educação básica no Brasil}

Conforme disposto no artigo XXVI da Declaração Universal dos Direitos Humanos (ONU) (1948), todo ser humano tem direito à instrução gratuita, pelo menos nos graus elementares e fundamentais. Ademais, é orientada no sentido de desenvolver plenamente a personalidade humana e fortalecer o respeito pelos direitos humanos e pelas liberdades fundamentais. $\bigcirc$ artigo ainda prescreve a obrigatoriedade da instrução elementar, ao mesmo tempo em que dispõe que os pais têm prioridade de direito na escolha do gênero de instrução que será ministrada aos filhos.

A Convenção sobre os Direitos da Criança, incorporada ao ordenamento jurídico pátrio pelo Decreto n. 99.710 (BRASIL, 1990a), prevê, em seu art. 18, que os Estados-partes envidarão os seus melhores esforços a fim de assegurar o reconhecimento do princípio de que ambos os pais têm obrigações comuns em relação à educação e ao desenvolvimento da criança. Cabe a eles ou, quando for o caso, aos representantes legais, a responsabilidade primordial pela educação e pelo desenvolvimento da criança.

Ainda de acordo com o documento internacional, os Estados-partes prestarão assistência adequada aos pais e aos representantes legais para o desempenho de suas funções no que tange à educação da criança. Ainda, assegurarão a criação de instituições, instalações e serviços para o cuidado dos menores. $\bigcirc$ artigo 28 da Convenção materializa normativamente essa assistência, mediante previsão de uma série de obrigações dos Estados-partes. Compete-lhes, por exemplo, tornar o ensino primário obrigatório e disponível, gratuitamente, para todos, exigência que, aliás, também é indicada na Declaração Universal dos Direitos Humanos. ${ }^{4}$

No plano constitucional, o artigo 227 da Carta Magna assevera ser dever da família, da sociedade e do Estado garantir à criança, ao adolescente e ao jovem, com absoluta prioridade, o direito à vida, à saúde, à alimentação, à educação, ${ }^{5}$ ao lazer, à profissionalização, à cultura, à dignidade, ao respeito, à liberdade e à convivência familiar e comunitária.

Nos termos do art. 208 da Constituição Federal, o dever do Estado com a educação será efetivado mediante a garantia de:

I - educação básica obrigatória e gratuita dos 4 (quatro) aos 17 (dezessete) anos de idade, assegurada inclusive sua oferta gratuita para todos os que a ela não tiveram acesso na idade própria; II - progressiva universalização do ensino médio gratuito; III - atendimento educacional especializado aos portadores de deficiência, preferencialmente na rede regular de ensino; IV - educação infantil, em creche e pré-escola, às crianças até 5 (cinco) anos de idade; V - acesso aos níveis mais elevados do ensino, da pesquisa e da criação artística, segundo a capacidade

\footnotetext{
4 Note-se que o artigo 29 da Convenção resguarda a iniciativa privada, ao dispor que os regramentos impostos no artigo 28 não devem ser interpretados de modo a restringir a liberdade dos indivíduos ou das entidades de criar e dirigir instituições de ensino, desde que sejam respeitados os princípios protetores e que a educação ministrada em tais instituições esteja acorde com os padrões mínimos estabelecidos pelo Estado.

5 A propósito, o artigo 229 da CF/88 dispõe que os pais têm o dever de assistir, criar e educar os filhos menores, e os filhos maiores têm o dever de ajudar e amparar os pais na velhice, carência ou enfermidade.
} 
de cada um; VI - oferta de ensino noturno regular, adequado às condições do educando; VII - atendimento ao educando, em todas as etapas da educação básica, por meio de programas suplementares de material didático escolar, transporte, alimentação e assistência à saúde. (BRASIL, 1988).

Por outro lado, conforme salientado pelo Ministro Paulo Medina, nos autos do MS 7.407DF, é importante repisar que a Constituição erige, como diretriz do sistema educacional, o princípio da liberdade, traduzido na "liberdade de aprender, ensinar, pesquisar e divulgar o pensamento, a arte e o saber" (inc. II, art. 206). Especifica, assim, a garantia genérica da liberdade, assegurada no caput do art. $5^{\circ}$. Aliado à liberdade, o ordenamento constitucional assegura a coexistência ou pluralismo de ideias e de concepções pedagógicas e de instituições públicas e privadas de ensino (inc. III). ${ }^{6}$

No âmbito do direito infraconstitucional interno, o artigo 53 do Estatuto da Criança e do Adolescente (BRASIL, 1990b) assegura ao infante o direito à educação, visando ao pleno desenvolvimento de sua pessoa, preparo para o exercício da cidadania e qualificação para o trabalho. Em contraposição, enquanto o art. 54 prescreve o dever do Estado de assegurar à criança e ao adolescente o ensino fundamental, obrigatório e gratuito, o artigo 55 prevê a obrigação dos pais ou responsáveis de matricularem seus filhos ou pupilos na rede regular de ensino. A propósito, de acordo com o art. 246 do Código Penal, o crime de abandono intelectual está caracterizado quando o responsável legal deixa, sem justa causa, de prover a instrução primária de filho em idade escolar.

Outra importante fonte normativa sobre o direito à educação é a Lei n. 9.394 (BRASIL, 1996), que estabelece as diretrizes e bases da educação nacional. Segundo o seu artigo $1^{\circ}$, a educação abrange os processos formativos que se desenvolvem na vida familiar, na convivência humana, no trabalho, nas instituições de ensino e pesquisa, nos movimentos sociais e organizações da sociedade civil e nas manifestações culturais. Tem-se, pois, nova constatação de que o direito à educação ultrapassa as dimensões da instrução formal, caracterizando-se como um processo integrado que intenciona desenvolver diversas aptidões do ser humano, tanto para o trabalho quanto para a vida em sociedade.

Assim, parece não haver dúvida quanto: $1^{\circ}$ ) à preocupação do legislador brasileiro com a formação da criança e do adolescente; $2^{\circ}$ ) ao reconhecimento do papel primordial da família, seio genuíno de formação humana; $3^{\circ}$ ) ao fato de que o conteúdo do direito à educação vai muito além da garantia de alfabetização. A educação, definitivamente, precisa ser vista como um processo de formação integral indispensável para o desenvolvimento pleno do ser humano.

Em que pese a convergência normativa no que diz respeito à obrigatoriedade do ensino institucional básico a partir da idade de quatro anos, é preciso investigar se o sistema consagrado na Constituição vincula apenas o Estado ou se também vincula a família. Conforme assentado pelo Ministério Público nos autos do MS 7.407, o princípio da liberdade, previsto no art. 206 da

$\overline{6}$ Excerto extraído do voto do Ministro Paulo Medina nos autos do MS 7.407 - DF (2001/0022843-7). 
Constituição, de alguma forma, conduz à interpretação de que a obrigatoriedade da educação tem como inspiração teleológica a profilaxia do desleixo estatal.

Resulta daí a interpretação no sentido de que a obrigatoriedade se dirige exclusivamente ao Estado, que ganha eficácia somente nos locais em que a oferta de vagas seja inferior ao número de crianças em idade escolar. Onde houver suficiente oferta de escola, os preceitos constitucionais resultam inócuos. Não só isso, segundo essa orientação, as disposições constitucionais tornam-se inócuas quando a estrutura familiar dispensa a educação formal. Quando isso acontece, os pais, longe de estarem desobedecendo à lei, abrem mão de uma garantia e suprimem a deficiência do Estado.

Não obstante sejam inegáveis a quantidade e a qualidade dos regramentos normativos sobre a educação brasileira, o serviço público à disposição da população ainda revela claras demonstrações de deficiência. Informações coletadas pelo Movimento Todos pela Educação mostram, por exemplo, que, em 2014, apenas 4,2\% das escolas da rede pública possuíam toda a infraestrutura considerada adequada pelo Plano Nacional de Educação (PNE).

A penúria não é constatada apenas em relação aos equipamentos modernos utilizados como ferramentas de ensino. Dados do Censo Escolar de 2013 denunciavam a existência de 8,2 mil escolas sem energia elétrica. Em 2014, a rede pública estava mais conectada à internet (40,7\%) do que ao sistema de coleta de esgoto e fornecimento de água tratada (35,7\%). Nesse mesmo ano, elevados $8 \%$ dos estabelecimentos não eram atendidos por qualquer sistema formal de abastecimento, sem falar que apenas $30 \%$ da rede de escolas contavam com bibliotecas e quadras esportivas, e mais de 90\% não contavam com laboratórios de Ciências (A PRECARIEDADE..., 2014).

Não bastasse isso, segundo pesquisa realizada pela Faculdade Latino-Americana de Ciências Sociais (Flacso), em parceria com o Ministério da Educação e a Organização dos Estados Interamericanos (OEI), a violência verbal ou física atingiu $42 \%$ dos alunos da rede pública, entre março de 2015 e março de 2016 (MORRONE, 2016). Outrossim, dados levantados em 2013 pelo QEdu: Aprendizado em Foco, uma parceria entre a Meritt e a Fundação Lemann, demonstram que há tráfico de drogas nas proximidades de pouco mais de um terço (35\%) das escolas públicas brasileiras (TRÁFICO..., 2013).

A precariedade do serviço público de educação, além de demonstrar total ausência de comprometimento do poder público com a realização de um direito fundamental, legitima a utilização de mecanismos alternativos de educação, destinados ao desenvolvimento multidimensional do menor.

Afinal, se o Estado não cumpre os diversos mandamentos que preconizam a entrega satisfatória de um serviço público de educação, inevitável indagar por que a população estaria obrigada a se submeter à obrigatoriedade do ensino institucional básico. Imagine-se, por exemplo, o caso de uma mãe pedagoga que, receosa, em razão dos altos índices de violência na escola pública de sua comunidade, acabe optando pela educação familiar. Seria razoável imputar a ela a prática do crime de abandono intelectual e a possível suspensão ou perda da guarda de seu filho? 


\section{A educação domiciliar}

O ensino domiciliar, também conhecido como homeschooling, é uma modalidade de educação realizada no âmbito domiciliar, normalmente exercida pelos pais, responsáveis ou preceptores sob supervisão, e não por uma instituição de ensino autorizada pelo poder público, com imposição de percentual mínimo de frequência.

Para os adeptos da educação domiciliar, considera-se que os pais têm o dever de assegurar a educação de seus filhos, e os filhos, o direito de receber uma educação significativa, inclusive por meio de instituições privadas, mas sempre conduzida de maneira primordial pelos genitores e/ou responsáveis legais.

Nos primórdios da civilização, a educação das crianças e adolescentes acontecia no âmbito domiciliar. No Brasil, a história da educação iniciou-se com a religião, por meio dos Jesuítas. Em 1824, durante o Império, foi outorgada a primeira Constituição brasileira, que recepcionou o direito à educação, em seu art. 179, incisos XXXII e XXXIII. Naquela época, foi estabelecida a garantia do ensino primário a todos os cidadãos, com a realização, de preferência, pela família e pela Igreja. ${ }^{7}$ (BRASIL, 1824).

Ou seja, a educação domiciliar, por muito tempo, foi aceita pela população como a forma primordial de instrução de seus filhos. Somente em 1934, com a vigência da Constituição dos Estados Unidos do Brasil, a educação ganhou força e importância, quando recebeu um capítulo específico intitulado de Da educação e da Cultura; e tal Constituição destaca-se como a primeira a reconhecer, no Brasil, de forma expressa, o direito à educação como um direito subjetivo, a ser ofertado pela família e pelo Estado (SÃO JOSÉ, 2014, p. 116-117).

Tanto verdade que a Lei de Diretrizes e Bases da Educação Nacional (BRASIL, 1961) informava, em seu artigo $2^{\circ}$, que a educação, direito de todos, necessitaria ser oferecida no lar e na escola, sendo a família responsável por escolher a maneira com a qual iria educar sua prole.

Sem embargo, conforme já salientado, conquanto o texto constitucional de 1988 preconize o dever do Estado de prestar educação básica, ele é omisso no que concerne à educação domiciliar. A anomia permanece até os dias atuais e envolve todos os planos normativos (constitucional e infraconstitucional).

De outro lado, em termos globais, a educação domiciliar é bastante difundida, sendo aceita em mais de 60 países. Trata-se de uma modalidade de educação cuja regulamentação não obedece a um padrão uniforme. Na Irlanda, por exemplo, utiliza-se o sistema conhecido como home, school, comunity liaison scheme (HSCL), que objetiva dar suporte aos alunos marginalizados, capacitar os pais e promover a aliança escola-família (SÃO JOSÉ, 2014). Já nos Estados Unidos, a modalidade de

\footnotetext{
7 São José (2014, p. 112 e ss.) traça, em sua obra, uma linha histórica brasileira sobre a educação primária em O homeschooling sobre a ótica do melhor interesse da criança e do adolescente.
} 
educação domiciliar é amplamente aceita em diversos estados, divergindo apenas quanto à regulação e à rigidez adotada em relação ao acompanhamento; os modelos mais rígidos, v.g., exigem que os pais enviem notificação, pontuação de testes e/ou avaliações profissionais. ${ }^{8}$ No caso americano, conforme o State Policies on Homeschooling (EDUCATION COMMISSION OF THE STATES, 2009), a Flórida é um dos Estados com elevado grau de ingerência estatal. Lá, os alunos educados em casa devem ser avaliados anualmente. Caso não demonstrem evolução no aprendizado domiciliar, os pais ou responsáveis têm um ano para reverter o quadro deficitário. Ou seja, a participação paterna encontra-se sob a vigilância do estado, que poderá recorrer ao "plano de remediação", hipótese em que o aluno poderá ser obrigado a retornar à sala de aula (SÃO JOSÉ, 2014).

\section{Vantagens e críticas acerca da educação domiciliar ou homeschooling}

A educação de uma criança ou adolescente em plena formação não se resume à transmissão de conteúdo tradicional. Perpassa também por valores e ensinamentos. E, como se sabe, cabe à família ou responsável educar as crianças, para que possam exercer o seu papel na sociedade.

Ao mesmo tempo, cabe à escola ensinar como tal. Ambas as relações são imprescindíveis, e não se pode imaginar a possibilidade de substituir uma pela outra. Em contrapartida, às famílias é garantida a livre autonomia para educar seus filhos como melhor thes aprouver.

Para melhor entendimento sobre os tipos de educação familiar e escolar, é importante esclarecer a diferença entre a educação formal, prestada pelo Estado, e a educação informal, prestada pela família. Biersdof (2011) entende que o papel da família é a educação informal, a fim de transmitir os costumes básicos humanos, a exemplo da comunicação e da alimentação, bem como os valores e as identidades culturais, como a religião e o respeito ao próximo. De outro lado, na educação formal, conduzida pelas instituições de ensino e de responsabilidade do Estado, remanesce o encargo de ensinar ciências.

O número de famílias que optam por educar seus filhos em casa vem crescendo no Brasil (HOMESCHOOLING..., 2017). Geralmente, opta-se por essa modalidade de ensino em razão dos seguintes aspectos: ideologia religiosa, limitações de saúde, crianças superdotadas e dificuldades de acesso, este último presente quando a família reside em localidades remotas ou ainda quando muda de residência com bastante frequência.

A escolha de não enviar os filhos à escola e tomar para si a responsabilidade e o dever de educar os filhos possui diversas justificativas. Pode decorrer do desejo dos pais de estarem mais próximos dos filhos e de acompanhar sua evolução, instrução e desenvolvimento.

Eventualmente, opta-se pelo modelo de ensino domiciliar em razão de experiências familiares com rotinas exóticas, como viagens pelo mundo, ou pelo desejo de proteção contra o

8 Para informações sobre o posicionamento dos Estados americanos em relação ao homeschooling, acessar o relatório State Policies on Homeschooling. 
bullying e a violência escolar. Ainda, pode estar associada a critérios de ordem pedagógica, religiosa ou filosófica, bem como ser a única solução viável nos casos de problemas de saúde ou limitações de aprendizado dos filhos.

Nussbaum (2013, p. 253), quando fala de justiça social, entende ser responsabilidade do Estado o apoio à educação especial, quando afirma que:

Mas, para os propósitos da lei, o reconhecimento básico da individualidade está acima de tudo: assim, quando uma criança parece beneficiar-se mais de uma educação especial do que de uma educação corrente, exige-se que o estado apoie tal alocação especial. Quando deve ser assim? Primeiro, pode haver casos nos quais o nível cognitivo de uma criança está tão fora do ritmo daquele das outras crianças da sua idade que poderá ser alcançado mais progresso através de uma educação especial. Segundo, há casos nos quais os problemas das crianças incluem dificuldades de comportamento que levariam provavelmente à estigmatização e ao ostracismo.

Em acréscimo, o comprometimento paterno com o desenvolvimento integral e escolarização dos filhos não pode ser esquecido, sem falar do direito à convivência familiar e comunitária, da instrução científica, da preparação para a vida adulta mais eficaz, dos valores e princípios cristãos, ${ }^{9}$ da proteção e, finalmente, do exercício de um Dever-Direito Fundamental, poder natural familiar (ANDRADE, 2014, p. 43).

Os críticos do ensino domiciliar exaltam a necessidade de convivência entre crianças e adolescentes de idades semelhantes, imprescindível para o desenvolvimento de habilidades de socialização. Em contraponto, pode-se dizer que o modelo de ensino domiciliar autoriza o convívio da criança com pessoas de diversas faixas etárias e, consequentemente, a visão de diferentes perfis comportamentais.

Outra possível fissura do modelo em comento consiste na possibilidade de a criança ou o adolescente ficar muito tempo sozinho em sua residência. Isso pode acontecer ou não. Devido às múltiplas opções de rotina pedagógica elaboradas pelos pais, os filhos têm oportunidade de visitar diversos ambientes e conviver com outros pais e crianças que compartilham a mesma experiência. Em muitos países, por meio das redes sociais, os genitores participam de grupos, organizam encontros sociais e aulas coletivas. Os estudantes vão ao cinema e ao museu. As mães se alternam, e cada uma ensina temáticas de acordo com as suas aptidões (SÃO JOSÉ, 2014).

Sen (2010) preconiza a liberdade como capacidade precípua para o desenvolvimento do ser humano e da sociedade. A liberdade é essencial para que o ser humano desenvolva sua autonomia e, com isso, seja apto a participar ativamente da sociedade. Com a educação não carece ser diferente.

\footnotetext{
9 Edson Prado inclusive informa que, no Brasil, predomina entre os agentes que lideram o Movimento pela Educação Familiar Desescolarizada no Brasil, bem como entre os pais e crianças que optam pela prática do modelo, famílias que se orientam pela fé cristã, em suas mais diversas formas e denominações. Entre alguns, há a convicção de que o sistema público de ensino se encontra realizando uma espécie de doutrinação ideológica materialista e niilista, amoral e imoral, que vilipendia a educação que desejam proporcionar aos seus próprios filhos, orientada por suas próprias crenças cristãs e modo de vida.
} 
Afinal, uma sociedade que se preocupa com a educação se preocupa também com o desenvolvimento pleno do ser humano.

Em verdade, o motivo precípuo para a escolha deve girar em torno da liberdade individual e do respeito ao pluralismo de ideias. A família é livre para escolher a educação que entende mais adequada para seus filhos. $O$ respeito à individualidade e à dignidade humana são essenciais para $\mathrm{O}$ desenvolvimento da plena capacidade (NUSSBAUM, 2013).

De fato, o ideal seria uma relação sinérgica entre escola e família. Porém, infelizmente, esta não parece ser a realidade brasileira, já que o Estado não cumpre a função constitucional de proporcionar educação universal de qualidade. Dessa forma, o homeschooling lança-se como alternativa de ensino aos educandos.

\section{A tutela da educação domiciliar no Brasil. Autonomia privada da família ou atuação excessiva do Estado?}

Atualmente, o Estado brasileiro não reconhece o direito dos pais de promoverem a educação domiciliar de seus filhos. Impõe a eles a obrigação de matrícula e frequência escolar dessas crianças e adolescentes, sob pena de responsabilidade nas esferas administrativa, civil e penal.

Posições favoráveis à educação domiciliar vêm ganhando força. Além do respeito ao pluralismo de ideias, houve a tomada de consciência de liberdade do exercício do poder familiar, ou seja, o alvedrio que os pais têm de escolher a maneira que lhe melhor aprouver para a educação de seus filhos.

O que ocorre é que, de acordo com as normas brasileiras, é obrigatória a matrícula escolar de crianças a partir de quatro aos 17 anos, sendo silente a legislação no que concerne à educação domiciliar, o que pode significar uma restrição indireta ao modelo de educação em comento.

Desde 1994 existem proposições normativas que buscam regulamentar a educação domiciliar no Brasil. Ao total, foram seis propostas de alteração de legislação e uma proposta de alteração da Constituição de 1988. Finalmente, em 08 de fevereiro de 2012, o Deputado Lincoln Portela apresentou proposta com o fito de alterar a legislação brasileira, para incluir a possibilidade de educação domiciliar, por meio do Projeto de Lei n. 3.179.

Tal projeto pretende alterar a LDBEN/96, acrescentando parágrafo ao art. 23, para possibilitar a oferta de educação domiciliar. O Projeto de Lei em comento prevê regulação por meio de avaliações periódicas, com vinculação a instituições de ensino, e demais requisitos. Estão presentes restrições no que concerne ao acompanhamento do aprendizado do aluno por parte do Estado, nos seguintes termos:

$\int 3^{\circ}$ É facultado aos sistemas de ensino admitir a educação básica domiciliar, sob a responsabilidade dos pais ou tutores responsáveis pelos estudantes, observadas a articulação, supervisão e avaliação periódica da aprendizagem pelos órgãos 
próprios desses sistemas, nos termos das diretrizes gerais estabelecidas pela União e das respectivas normas locais. (CÂMARA DOS DEPUTADOS, 2012).

Apesar de reconhecer a importância de tal projeto de lei, a sua aprovação não implica que homeschooling seria um exercício de autonomia privada dos pais, mas uma mera concessão do Estado. Quando faculta a admissão do instituto ao arbítrio do governo, apenas se limita a criar uma falsa expectativa de autonomia, que pressupõe o aval do Estado para existir.

Atualmente, tal Projeto de Lei se encontra aguardando apreciação pela Comissão de Educação da Câmara dos Deputados. Apenso a esse projeto, existe o Projeto de Lei n. 3.261/2015, de autoria de Eduardo Bolsonaro. Neste, é sugerida a autorização do ensino domiciliar na educação básica, formada por educação infantil, ensino fundamental e ensino médio para os menores de 18 anos.

Nesse Projeto de Lei (CÂMARA DOS DEPUTADOS, 2015), impende ressaltar, recomendase que a educação domiciliar seja uma espécie de matrícula especial, e sugere-se que é dever dos pais ou responsáveis efetuar a matrícula das crianças na educação básica a partir dos quatro anos de idade, inclusive quando optarem pelo ensino domiciliar.

Portanto, o pretenso avanço na autonomia da liberdade, com a aprovação dos mencionados projetos de lei, seria apenas um mito. Ou seja, mais uma forma de dominação do Estado para com a sociedade, pois os pais continuarão obrigados a cumprir requisitos na educação de seus filhos, os quais cerceiam sua autonomia privada.

No âmbito judicial, em 2015, o Supremo Tribunal Federal recebeu o Recurso Extraordinário n. 888.815/2005, oriundo de Mandado de Segurança impetrado em Canela, Rio Grande do Sul, contra ato da Secretária de Educação do Município mencionado. Os impetrantes, à época, ao solicitarem ao órgão a autorização para educar a filha em regime domiciliar, receberam, em sentido contrário, a recomendação de imediata matrícula na rede regular de ensino. Ao julgar a demanda, o Tribunal de origem entendeu que não haveria direito líquido e certo a amparar o pedido da recorrente de ser educada em regime domiciliar.

O recurso encontra-se em trâmite perante o Supremo Tribunal Federal, e busca fundamento no art. 102, III, a, da Constituição Federal. A parte recorrente alega violação aos arts. 205, 206, 208, 210, 214 e 229, todos da CF/88. Em 04 de junho de 2015 foi reconhecida a Repercussão Geral do presente tema, ou seja, decidiu-se que compõe questão constitucional saber se o ensino domiciliar deve ser proibido pelo Estado ou meio lícito de cumprimento, pela família, do dever de prover educação, como previsto no art. 205 da CRFB/1988. ${ }^{10}$

\footnotetext{
$\overline{10}$ Ementa: DIREITO CONSTITUCIONAL. EDUCAÇÃO. ENSINO DOMICILIAR. LIBERDADES E DEVERES DO ESTADO E DA FAMÍLIA. PRESENÇA DE REPERCUSSÃO GERAL. 1. Constitui questão constitucional saber se o ensino domiciliar (homeschooling) pode ser proibido pelo Estado ou viabilizado como meio lícito de cumprimento, pela família, do dever de prover educação, tal como previsto no art. 205 da CRFB/1988. 2. Repercussão geral reconhecida. Decisão: O Tribunal, por maioria, reputou constitucional a questão, vencidos os Ministros Dias Toffoli e Teori Zavascki. Não se manifestaram as Ministras Cármen Lúcia e Rosa Weber. O Tribunal, por maioria, reconheceu a existência de repercussão geral da questão constitucional suscitada, vencidos os Ministros Dias Toffoli e Teori Zavascki. Não se manifestaram as Ministras Cármen Lúcia e Rosa Weber.
} 
Atualmente, em agosto de 2017, foi prolatado despacho deferindo o ingresso no processo, na qualidade de amici curiae, da União, estados do Acre, Alagoas, Amazonas, Goiás, Espírito Santo, Maranhão, Mato Grosso, Mato Grosso do Sul, Minas Gerais, Paraíba, Pernambuco, Piauí, Rio de Janeiro, Rio Grande do Norte, Rondônia, Santa Catarina, São Paulo, Sergipe, Distrito Federal, Rio Grande do Sul e Associação Nacional de Educação Domiciliar (ANED). Inclusive, nos autos, já existe parecer do Procurador-Geral da República, que se manifestou nos seguintes termos:

[...] Ante o exposto, o parecer é pelo conhecimento e desprovimento do recurso extraordinário, tendo em vista reconhecer que, embora seja constitucionalmente possível a adoção de algum modelo de eleição do ensino básico domiciliar no Brasil, desde que resguardado o projeto constitucional de socialização e formação plena do educando, essa solução depende exclusivamente de lei que venha a ser aprovada pelo Congresso Nacional.

Portanto, quanto ao pedido da recorrente V. D., representada por M. P. D., manifesta-se a Procuradoria-Geral da República pela confirmação do acórdão recorrido, o qual entendeu pela inexistência de direito líquido e certo ao sistema de educação domiciliar. (RIO GRANDE DO SUL, 2015).

Pelo que se conclui, o Procurador-Geral da República manifestou-se no sentido de que é constitucionalmente possível a adoção de modelo de ensino básico domiciliar no Brasil, desde que haja controle e regulamentação, que, por sua vez, deve ser feita por meio de Lei que venha a ser aprovada pelo Congresso Nacional.

Não se pode interpretar o tema de maneira estrita. Deve-se, isso sim, considerar o papel da família e sua liberdade de escolher a forma de educar os filhos. Sendo pelo homeschooling, que sejam observadas determinadas diretrizes estabelecidas pelo Estado, até porque o excesso de liberdade não parece ser uma alternativa prudente, haja vista a necessidade de tutelar o interesse do menor.

A obrigação do ensino da criança e do adolescente deve ser compartilhada entre o Estado, a sociedade e a família. Porém, as intervenções do Estado na vida privada devem ser mínimas, não podendo estabelecer entraves ou mitigar a liberdade humana de como os pais escolhem educar seus filhos. Ao compreender-se a matéria de modo diverso, valoriza-se a ideia de Estado paternalista, que tolhe a liberdade de aprender, ensinar, pesquisar e divulgar o pensamento, a arte e o saber.

Por paternalismo entende-se a noção de que alguém, que se considera ter discernimento superior, seja capaz de tutelar aquela sociedade com vistas ao bem daqueles que nela vivem (MIGUEL, 2015). Não por acaso, a expressão faz alusão ao substantivo "pai”, aquele que tutela e protege seus filhos por um bem maior, trazendo, inclusive, uma ideia de utilitarismo ${ }^{11}$ para a assunção das escolhas.

Sob outro viés, a ideia de paternalismo está intrinsecamente vinculada à concepção de liberdade. Isso se deve à convenção de limitar a esfera de liberdade individual (positiva ou negativa) para garantir outros valores fundamentais para o próprio indivíduo e também para os "outros sociais" (LEITÃO; DIAS; CIDRÃO, 2017).

11 "O utilitarismo pressupõe um interesse universal e espontâneo (a maximização da utilidade), que é comum e uniforme em todos os indivíduos, e que, portanto, não é objeto de investigação." (MIGUEL, 2015, p. 605). 
O modo como o paternalismo se manifesta depende de recortes epistemológicos. De acordo com Miguel (2015), a forma mais relevante é o paternalismo público, segundo o qual o Estado patrocina políticas públicas que visam a impedir que os cidadãos tomem decisões incorretas ou, pelo menos, que pretendem direcioná-los para decisões acertadas.

Sunstein e Thaler (2003) defendem a posição do paternalismo suave. Garante-se a possibilidade de escolha pelo indivíduo, cabendo ao Estado promover esclarecimentos sobre as possibilidades. Deve, ainda, reduzir ou ampliar custos das diferentes alternativas para facilitar ou até determinar a escolha da melhor opção. Para ele, trata-se de uma forma de paternalismo que não conspurca a escolha individual. Somente visa a favorecer alternativas que contribuam para a sociedade.

No caso de relações em Estado paternalista, naturalmente se vislumbra uma forma de dominação. O que não pode ocorrer é o impedimento das formações de preferências pessoais, imposto através da dominação. Nesse sentido, não pode o Estado preponderar sobre o poder familiar, a ponto de os pais sequer imaginarem outras possibilidades de transmissão de ensino formal aos seus filhos. De outro lado, não podem os pais exercer dominação sobre seus filhos, por meio da imposição crítica e da impossibilidade de ampliação do acesso às informações e visões alternativas de mundo.

Em contraponto ao posicionamento do paternalismo está o liberalismo. A liberdade e a pluralidade de escolha devem fazer parte da sociedade, que inclui pessoas com personalidade e escolhas diferentes. As mudanças são constantes, as necessidades são diferentes, e a imposição de um modelo único tolhe as escolhas individuais.

Sobre o pensamento liberal, pode-se entender, em linhas gerais, a capacidade de um indivíduo autônomo de decidir sua vida por conta própria. O sujeito é autônomo quando é livre para determinar seu comportamento, assumir suas responsabilidades e guiar-se por seus próprios critérios, na formulação de suas escolhas, quer sejam elaborados por ele mesmo, quer sejam adotados por conta própria (MIGUEL, 2015).

É imprescindível autonomia para o exercício da liberdade dos direitos. Nesse sentido, Ralws (2000) pondera que as pessoas são respeitadas em sua liberdade e igualdade em virtude de possuírem duas faculdades da personalidade moral: a capacidade de ter senso de justiça e a capacidade de ter uma concepção do bem.

Sucede que, para prevalecer o melhor interesse da criança e do adolescente, é fundamental que exista, ainda que minimamente, a intervenção do Estado, para acompanhar a evolução do aprendizado, afinal, trata-se de interesse social o pleno desenvolvimento das crianças e adolescentes.

\section{Conclusão}

Diante do exposto, verifica-se que o Estado pode estabelecer padrões de ensino, mas não pode interferir na autonomia e na liberdade dos pais. Exatamente por isso, deve-se garantir o direito 
à educação domiciliar no Brasil, cabendo às autoridades locais a realização de intervenções sempre que for constatado que os pais não estão provendo uma educação apropriada às crianças.

A sociedade atual demanda novas escolhas, valores e liberdades. A escola baseada em modelos engessados e dogmáticos necessita de reflexão e atualização. Impende modificar o paradigma da escola solidificada em um modelo em que as pessoas eram educadas a se ajustar ao formato do mundo estático, para priorizar a liberdade de pensamento crítico e de escolha.

Impõe-se, pois, a regulamentação do tema, a fim de que os pais tenham a tranquilidade de optar pela educação domiciliar. Compete ao Estado acompanhar e promover intervenções pontuais segundo critérios preestabelecidos. Sugere-se que as medidas de poder envolvam entrevistas, visitas domiciliares, acompanhamentos curriculares e, em último caso, a suspensão do ensino domiciliar (re-escolarização).

Espera-se que o Congresso Nacional aprove a liberação do ensino domiciliar e passe a regulamentá-lo como uma das modalidades de ensino no País, inclusive mediante exigência de inscrição em estabelecimento de ensino a distância e aplicação de controles regulares que obrigam a re-escolarização do menor, em caso de resultados insatisfatórios.

Finalmente, diante das ponderações acerca de paternalismo e suas variações, dominação e liberalismo, deve prevalecer a vontade da família no que tange à escolha da educação dos filhos, cabendo ao Estado fiscalizar a qualidade da educação ofertada.

\section{Referências}

A PRECARIEDADE física da rede escolar. O Globo, 01 jun. 2014. Disponível em: <https://oglobo. globo.com/opiniao/a-precariedade-fisica-da-rede-escolar-12349275>. Acesso em: 20 jun. 2017.

ALMEIDA, Felipe Quintão de; GOMES, Ivan Marcelo; BRACHT, Vitor. Dilemas e Desafios da Educação na Atualidade: Uma Leitura com Bauman. In: SIMPÓSIO NACIONAL DE EDUCAÇÃO, 1., 2008, Cascavel. Anais... Cascavel: Unioeste, 2008. Disponível em: <http://www.unioeste.br/ cursos/cascavel/pedagogia/eventos/2008/6/Artigo\%2005.pdf>. Acesso em: 25 jul. 2017.

ANDRADE, Édison Prado de. Homeschooling: uma abordagem à luz dos diplomas internacionais de direitos humanos aplicáveis à criança e ao adolescente. Revista de Direito da Unianchieta, n. 21, n. 14, p. 21-87, 2014.

BAUMAN, Z. Modernidade líquida. Rio de Janeiro: Zahar, 2001.

BIERSDORF, R. K. O papel da educação formal e informal: educação na escola e na sociedade. Revista Eletrônica do curso de pedagogia do Campus Jataí, Universidade Federal de Goiás, v. 1, n. 10, p. 1-13, 2011.

BRASIL. Constituição. Constituição Política do Império do Brasil de 1824. Outorgada em 25 de março de 1824. Disponível em: <http://www.planalto.gov.br/ccivil_03/constituicao/constituicao24. htm >. Acesso em: 20 jun. 2017. 
BRASIL. Constituição. República Federativa do Brasil de 1988. Brasília, DF: Senado Federal, 1988. Disponível em: <https://www2.senado.leg.br/bdsf/bitstream/handle/id/518231/CF88_Livro_ EC91_2016.pdf>. Acesso em: 20 jun. 2017.

BRASIL. Decreto n. 99.710 de 21 de novembro de 1990. Promulga a Convenção sobre os Direitos da Criança. Diário Oficial da República Federativa do Brasil, DF, de 22 de nov. 1990a.

BRASIL. Lei n. 4.024, de 20 de dezembro de 1961. Fixa as Diretrizes e Bases da Educação Nacional. Diário Oficial da União, Brasília, DF, 27 dez. 1961.

BRASIL. Lei n. 8.069 de 13 de julho de 1990. Dispõe sobre o Estatuto da Criança e do Adolescente e dá outras providências. Diário Oficial da União, Brasília, DF, 16 jul. 1990 b.

BRASIL. Lei n. 9.394 de 20 de dezembro de 1996. Estabelece as diretrizes e bases da educação nacional. Diário Oficial da União, Brasília, DF, 23 dez. 1996.

CÂMARA DOS DEPUTADOS. Projeto de Lei n. 3.179/2012. Acrescenta parágrafo ao art. 23 da Lei no 9.394, de 1996, de diretrizes e bases da educação nacional, para dispor sobre a possibilidade de oferta domiciliar da educação básica. 18 fev. 2012. Disponível em: <http://www.camara.gov.br/ proposicoesWeb/prop_mostrarintegra? codteor $=963755 \&$ filename $=P L+3179 / 2012>$. Acesso em: 12 jun. 2017.

CÂMARA DOS DEPUTADOS. Projeto de Lei no 3.261/2015. Acrescenta alínea ao inciso II do art. $8^{\circ}$ da Lei $\mathrm{n}^{\circ} 9.250$, de 26 de dezembro de 1995, para incluir as despesas com atividades físicas nas hipóteses de dedução da base de cálculo do imposto de renda das pessoas físicas. 08 out. 2015. Disponível em: <http://www.camara.leg.br/buscaProposicoesWeb/resultadoPesquisa?tipoproposicao $=$ PL +-+ Projeto + de + Lei\&data $=21 \% 2 F 05 \% 2 F 2018 \&$ page $=$ false\&emtramitacao $=$ Todas $\&$ nu mero $=3261 \& a n o=2015>$. Acesso em: 12 jun. 2017.

EDUCATION COMMISSION OF THE STATES. State Policies on Homeschooling. Disponível em: <https://www.ecs.org/clearinghouse/82/30/8230.pdf>. Acesso em: 08 jun. 2017.

GIDDENS, Anthony. As consequências da modernidade. São Paulo: Unesp, 1991.

HOMESCHOOLING: Brasil já tem 6 mil crianças sendo educadas em casa. Revista Crescer, 11 jan. 2017. Disponível em: <http://revistacrescer.globo.com/Criancas/Escola/noticia/2017/ 01/homeschooling-brasil-ja-tem-6-mil-criancas-sendo-educadas-em-casa.html> . Acesso em: 12 jun. 2017.

LEITÃO, André Studart; DIAS, Eduardo Rocha; CIDRÃO, Taís Vasconcelos. Paternalismo: uma ideia viável? Revista Direito e Desenvolvimento, v. 8, p. 273-288, 2017.

MIGUEL, Luis Felipe. Autonomia, paternalismo e dominação na formação das preferências. Opinião Pública, Campinas, v. 21, n. 3, p. 601-625, dez. 2015.

MORRONE, Beatriz. Violência atinge 42\% dos alunos da rede pública. O Globo, 23 mar. 2016. Disponível em: <http://epoca.globo.com/vida/noticia/2016/03/violencia-atinge-42-dos-alunos-da-rede-publica.html>. Acesso em: 20 jun. 2017.

MOVIMENTO todos pela Educação. Observatório do plano nacional de educação. Disponível em: <http://www.observatoriodopne.org.br/>. Acesso em: 04 nov. 2017. 
NUSSBAUM, M. C. Fronteiras da Justiça: Deficiência, nacionalidade, pertencimento à espécie. Tradução Suzana Castro. São Paulo: WMF Martins Fontes, 2013.

ORGANIZAÇÃO DAS NAÇÕES UNIDAS. Declaração Universal dos Direitos Humanos. 10 dez. 1948. Disponível em: <http://www.onu.org.br/img/2014/09/DUDH.pdf>. Acesso em: 20 jun. 2017.

RAWLS, J. O Liberalismo político. São Paulo: Ática, 2000.

RIO GRANDE DO SUL. Parecer do Procurador-Geral da República no Recurso Extraordinário no 888.815 do Rio Grande do Sul. Relator: Ministro Roberto Barroso. Órgão Julgador: Plenário. Julgamento em 04 jun. 2015. Disponível em: <http://redir.stf.jus.br/paginadorpub/paginador.jsp?docTP=TP\&do$\mathrm{cID}=8678529>$. Acesso em: 12 jun. 2017.

RIO GRANDE DO SUL. Recurso Extraordinário no 888.815-RS. Recorrente: V D representada por M P D. Recorrido: Município de Canela. Relator: Ministro Roberto Barroso. Brasília, DF, 17 jul. 2018. Disponível em: <http://portal.stf.jus.br/processos/detalhe.asp?incidente $=4774632>$. Acesso em: 20 jul. 2018.

SÃO JOSÉ, Fernanda Moraes de. O Homeschooling sob a ótica do melhor interesse da criança e do adolescente. Belo Horizonte: Del Rey, 2014.

SEN, Amartya. Desenvolvimento como liberdade. São Paulo: Companhia das Letras, 2010.

SUNSTEIN, Cass R.; THALER, Richard H. Libertarian Paternalism. American Economic Review, v. 93, p. 175-179, May 2003. Disponível em: <https://www.aeaweb.org/atypon.php?doi=10.1257/ $000282803321947001>$. Acesso em: 20 jun. 2017.

TRÁFICO de drogas está perto de 35\% das escolas públicas brasileiras. IG São Paulo, 05 fev. 2013. Disponível em: <http://ultimosegundo.ig.com.br/educacao/2013-02-05/trafico-de-drogas-esta-perto-de-35-das-escolas-publicas-brasileiras.html >. Acesso em: 20 jun. 2017.

Data da submissão: 22 de dezembro de 2017 Avaliado em: 14 de maio de 2018 (AVALIADOR A) Avaliado em: 15 de maio de 2018 (AVALIADOR B) Aceito em: 08 de julho de 2018 